\title{
ALMOST EVERYWHERE CONVERGENCE OF DYADIC TRIANGULAR-FEJÉR MEANS OF TWO-DIMENSIONAL WALSH-FOURIER SERIES
}

\author{
GYÖRGY GÁT AND USHANGI GOGINAVA
}

Abstract. It is proved that the maximal operators of the dyadic triangular-Fejér means of twodimensional Walsh-Fourier series is of weak type $(1,1)$. Moreover, the dyadic triangular-Fejér means of the function $f \in L_{1}$ converge almost everywhere to $f$ as $n \rightarrow \infty$.

Mathematics subject classification (2010): 42C10.

Keywords and phrases: Two-dimensional Walsh system, triangular means, Hardy spaces, almost everywhere summability.

\section{REFERENCES}

[1] J. Fine, Cesàro summability of Walsh-Fourier series, Proc. Nat. Acad. Sci. U.S.A., 41, (1955), 588591.

[2] N. J. FUJII, A maximal inequality for $H^{1}$-functions on a generalized Walsh-Paley group, Proc. Amer. Math. Soc., 77, 1 (1979), 111-116.

[3] G. GÁt, U. Goginava And G. Tkebuchava, Convergence in measure of logarithmic means of quadratical partial sums of double Walsh-Fourier series, J. Math. Anal. Appl., 323, 1 (2006), 535549.

[4] G. GÁt, U. Goginava And K. NaGy, On the Marcinkiewicz-Fejér means of double Fourier series with respect to the Walsh-Kaczmarz system, Studia Sci. Math. Hungar., 46, 3 (2009), 399-421.

[5] G. GÁT, On almost everywhere convergence and divergence of Marcinkiewicz-Like means of integrable functions with respect to the two-dimensional Walsh system, Journal of Approx. Theory 164, 1 (2012), 145-161.

[6] G. GÁt, U. Goginava, Triangular Fejér Summability of Two-Dimensional Walsh-Fourier series, Anal. Math. 40, 2 (2014), 83-104.

[7] U. Goginava, Marcinkiewicz-Fejér means of d-dimensional Walsh-Fourier series, J. Math. Anal. Appl., 307, 1 (2005), 206-218.

[8] U. Goginava, The maximal operator of Marcinkiewicz-Fejér means of the d-dimensional WalshFourier series, East J. Approx., 12, 3 (2006), 295-302.

[9] U. Goginava, Maximal operators of $(C, \alpha)$-means of cubic partial sums of $d$-dimensional WalshFourier series, Anal. Math., 33, 4 (2007), 263-286.

[10] U. Goginava, The weak type inequality for the Walsh system, Studia Math., 185, 1 (2008), 35-48.

[11] U. Goginava, The weak type inequality for the maximal operator of the Marcinkiewicz-Fejer means of the two-dimensional Walsh-Fourier series, J. Approx. Theory, 154, 2 (2008), 161-180.

[12] U. Goginava AND F. WeIsZ, Maximal operator of the Fejér means of triangular partial sums of two-dimensional Walsh-Fourier series, Georgian Math. J. 19, 1 (2012), 101-115.

[13] H. LeBesgue, Recherches sur la convergence des series de Fourier, Math. Ann., 61, 2 (1905), 251280.

[14] J. MARCIN KIEwicz, Sur une méthode remarquable de sommation des séries doubles de Fourier, Ann. Scuola Norm. Sup. Pisa Cl. Sci., 8, 2 (1939), 149-160.

[15] J. MarcinkiewiCZ AND A. ZyGmund, On the summability of double Fourier series, Fund. Math, 32, (1939), 122-132. 
[16] F. Schipp, Über gewisse Maximaloperatoren, Ann. Univ. Sci. Budapest. Eotvos Sect. Math. 18 (1975), 189-195 (1976).

[17] F. Schipp, W. R. Wade, P. Simon And J. PÁL, Walsh Series. An Introduction to Dyadic Harmonic Analysis, Adam Hilger, Ltd., Bristol, 1990.

[18] P. Simon, Investigations with respect to the Vilenkin system, Ann. Univ. Sci. Budapest. Eotvos Sect. Math, 27, (1984), 87-101 (1985).

[19] P. Simon, Cesàro summability with respect to two-parameter Walsh systems, Monatsh. Math. 131, 4 (2000), 321-334.

[20] F. WeISZ, Cesàro summability of one- and two-dimensional Walsh-Fourier series, Anal. Math., 22, 3 (1996), 229-242.

[21] F. WeIsZ, Convergence of double Walsh-Fourier series and Hardy spaces, Approx. Theory Appl. (N.S.), 17, 2 (2001), 32-44.

[22] F. WeIsz, Summability of Multi-Dimensional Fourier Series and Hardy Spaces, Mathematics and its Applications, 541. Kluwer Academic Publishers, Dordrecht, 2002.

[23] F. WeIsz, Triangular Cesàro summability of two-dimensional Fourier series, Acta Math. Hungar. 132, 1-2 (2011), 27-41.

[24] L. ZhizhiashVili, Generalization of certain theorem of Marcinkiewicz, Izv. Akad. Nauk SSSR Ser. Mat. 32, (1968), 1112-1122 (in Russian); translation in Math. USSR, Izv. 2, (1968), 1065-1075.

[25] L. ZhizhiashVili, Trigonometric Fourier Series and Their Conjugates, Mathematics and its Applications, 372. Kluwer Academic Publishers Group, Dordrecht, 1996.

[26] A. Zygmund, Trigonometric Series, Vol. I, II, Third edition. With a foreword by Robert A. Fefferman, Cambridge Mathematical Library, Cambridge University Press, Cambridge, 2002. 